Indo. J. Chem. Res., 2019, 6(2), 94-100

\title{
VALIDASI METODE PENENTUAN Mn DALAM OLI LUBRIKAN DENGAN METODE PENGENCERAN LANGSUNG MENGGUNAKAN SPEKTROFOTOMETER SERAPAN ATOM
}

\section{Validation Method on The Determination of Mn In Lubricating Oil by Direct Dilution Method Using Atomic Absorption Spectrometer}

\author{
Rona Maningting Napitupulu, Dirgarini Julia, Aman Sentosa Panggabean* \\ Chemistry Department, Faculty of Mathematics and Natural Sciences \\ Pattimura University, Universitas Mulawarman, Samarinda \\ *Corresponding author, e-mail: amanspanggabean@yahoo.com
}

Received: Dec. 2018 Published: Jan. 2019

\begin{abstract}
Validation method on the determination of $\mathrm{Mn}$ in lubricating oil by direct dilution method using Atomic Absorption Spectrophotometer (AAS) in Laboratory \& Environment Control PT. Badak NGL Bontang has been done The validation method was done with research stages such as determination of optimum solvent, and determination of some important parameters influential for validation method such as parameter of liniearitas (r), Instrument Detection Limit (IDL), Methode Detection Limit (MDL), accuracy, precision, Limit of Detection(LOD) and Limit of Quantitation(LOQ). The result of research obtain is good, showed that the linearity value with $\mathrm{R}^{2} \geq 0,997$. The IDL and MDL value was $0.0021 \mathrm{ppm}$ and $0.0092 \mathrm{ppm}$ respectively and has been acceptability requirements of MDL. The accuracy paramater obtained recovery value with range 82.25-88.34\%. The measurement of repeatability and reproducibility, the CV Horwitz value smaller than \% RSD, indicating the method had a good precision. The measurement of LOD and LOQ value was $0.095 \mathrm{ppm} 0.317 \mathrm{ppm}$ respectively. Based on the result of the research determination method of $\mathrm{Mn}$ in lubricating oil by direct dilution method using AAS concluded valid.
\end{abstract}

Keywords: Validation method, Mn, lubricating oil, direct dilution, AAS.

\section{PENDAHULUAN}

Setiap laboratorium kimia penting untuk memperhatikan Quality control (pengendalian mutu) untuk memberikan kepercayaan atas kualitas hasil pengujian yang diberikan. Metode yang digunakan di laboratorium kimia harus dievaluasi untuk menjamin bahwa metode yang digunakan mampu menghasilkan data yang valid dan dan dapat dipertanggungjawabkan dengan tingkat ketepatan dan ketelitian yang tinggi, maka metode tersebut harus divalidasi (Taufik dkk., 2016). Validasi metode merupakan proses penilaian terhadap suatu metode analisis yang berdasarkan dari hasil pengujian laboratorium dimana hasil pengujian tersebut dapat membutikan bahwa suatu metode sudah memenuhi syarat untuk digunakan (Harmita, 2004).

Pengembangan validasi metode telah banyak dikembangkan khususnya di Laboratorium kimia Analitik FMIPA Universitas Mulawarman, bekerjasama dengan beberapa industri yang berada di provinsi Kalimantan Timur, yang memiliki laboratorium penguji yang memadai dan tersertifikasi. Beberapa penelitian tentang validasi metode yang dapat dilaporkan adalah penentuan florin $\left(\mathrm{F}^{-}\right)$pada batubara dengan metode Spektrofotometer Visible (Adha dkk., 2017), pengembangan metode rapid tes dalam penentuan Inherent Moisture dan total sulphur yang dibandingkan dengan metode standard ISO (Destiana dkk., 2017). Hal ini menunjukkan bahwa validasi metode sangat penting dilakukan di laboratorium yang sudah terstandarisasi dengan baik.

Salah satu metode analisis yang dilakukan di Laboratory \& Environment Control PT. Badak NGL Bontang ialah analisis penentuan logam di dalam oli lubrikan menggunakan Spktrofotometer Serapan Atom (SSA). Oli lubrikan merupakan pelindung bagian-bagian yang saling bergerak pada mesin agar tidak terjadi gesekan langsung antar mesin. Hal yang perlu untuk diperhatikan pada oli lubrikan ialah 
kandungan logam berat yang berasal dari bahan bakar dan keausan pada mesin (Supriyanto dkk., 2016).

Mangan (Mn) merupakan logam komponen penyusun dari sebuah baja yang berfungsi untuk mengurangi sifat rapuh karena panas dan meningkatkan kekakuan pada baja, dimana baja adalah komponen penting pada suatu mesin produksi (Binudi, 2014). Tujuan dilakukannya penentuan $\mathrm{Mn}$ dalam oli adalah untuk mengetahui berapa konsentrasi Mn pada oli yang menunjukan kualitas oli lubrikan yang digunakan. Semakin tinggi kadar logam pada oli lubrikan maka semakin mengindikasikan keausan pada mesin

Bedasarkan latar belakang tersebut, pada penelitian ini dilakukan validasi metode penentuan Mn menggunakan Spektrofotometer Serapan Atom dengan metode pengenceran langsung yang didasarkan pada metode standar dari Agilent Procedure AA010 oleh McKenzie (2010) dan PC-1 Analysis of Lubricating Oils: Determination of Wear Metals pada buku Analytical Methods for Atomic Absorption Spectrophotometry oleh Perkin-Elmer Corporation (Anonim, 1996). Tahapan pada penelitian ialah optimasi pelarut, dan optimasi kinerja analitik dengan parameter liniearitas, akurasi, presisi, LOD (Limit of Detection), LOQ (Limit of Quantity), IDL (Instrument Detection Limit) dan MDL (Methode detection limit).

\section{METODOLOGI PENELITIAN}

\section{Bahan}

Bahan-bahan yang digunakan dalam penelitian ini adalah larutan blank oil, larutan standar logam Mn 50 ppm, n-Heksan, Thinner, MIBK (Methyl Isobutyl Ketone) dan sampel oli lubrikan yang diambil pada kompresor Train G. PT Badak NGL Bontang dan aquabidest.

\section{Alat}

Alat-alat yang digunakan dalam penelitian ini diantaranya, gelas kimia, pipet volume, pipet tetes, bulp, labu ukur, corong kaca, Spektrofotometer Serapan Atom Agilent Spectra AA 220 FS, lampu katoda Mn.

\section{Prosedur Kerja \\ Penentuan Pelarut Optimum}

Sebanyak $1 \mathrm{~mL}$ larutan larutan standar logam conostan 50 ppm ditambahkan ke dalam masing-masing labu ukur. Setelah itu, dilakukan pengenceran menggunakan pelarut $n$-Heksan, Thinner dan MIBK (Methyl Isobutyl Ketone) pada masing-masing labu ukur hingga tanda tera kemudian dihomogenkan. Kemudian, dilakukan pembacaan absorbansi menggunakan pelarut nHeksan, Thinner dan MIBK (Methyl Isobutyl Ketone).

\section{Optimasi Kinerja Analitik Linearitas}

Larutan blanko dan oli standar 0,$5 ; 1,0 ; 1,5$; 2,$0 ; 3,0 ; 4,0 ; 5,0 \mathrm{ppm}$ yang telah diencerkan menggunakan pelarut MIBK disiapkan. Setelah itu, dilakukan analisis dengan AAS. Kemudian nilai konsentrasi dan absorbansinya dicatat.

\section{Akurasi}

Larutan spike dan larutan sampel yang dipersiapkan dianalisis dengan AAS serta dicatat masing-masing nilai konsentrasi dan absorbansinya. Kemudian dilakukan pembacaan absorbansi dan konsentrasi pada masing-masing larutan sebanyak 10 kali. Nilai rata-rata konsentrasi digunakan untuk mentukan \% perolehan kembali.

\section{Presisi}

Larutan sampel yang telah diencerkan menggunakan pelarut MIBK dianalisis dengan AAS serta dicatat nilai konsentrasi dan absorbansi untuk larutan sampel. Kemudian dilakukan pembacaan absorbansi dan konsentrasi pada masing-masing larutan sebanyak 10 kali. Setelah data diperoleh, dihitung standard deviasi,\% KV Horwitz dan 2/3 \% KV Horwitz.

\section{Uji LOD}

Pada uji LOD dilakukan secara statistik melalui garis regresi linier dari kurva kalibrasi, dimana respon instrument y berhubungan linier dengan konsentrasi $x$. Besar limit deteksi biasanya dinyatakan dengan $3 \mathrm{Sa} / \mathrm{b}$, dimana $\mathrm{Sa}$ adalah standar deviasi dan $b$ adalah slope.

\section{Uji LOQ}

Pada uji LOD dilakukan secara statistik melalui garis regresi linier dari kurva kalibrasi, dimana respon instrument y berhubungan linier dengan konsentrasi $x$. Besar limit deteksi biasanya dinyatakan dengan $10 \mathrm{Sa} / \mathrm{b}$, dimana $\mathrm{Sa}$ adalah standar deviasi dan $b$ adalah slope. 


\section{Uji IDL dan MDL}

Larutan blanko yang telah dipreparasi disiapkan. Kemudian analisa dilakukan dengan SSA serta dicatat nilai konsentrasi dan absorbansinya untuk larutan blank. Setelah itu, Pembacaan konsentrasi pada masing-masing larutan sebanyak 10 kali dilakukan. Kemudian, nilai pada hasil pembacaan larutan blank dicatat. Setelah itu, dilakukan perhitungan untuk mendapatkan nilai IDL dan MDL. Lalu, larutan spike berdasarkan nilai IDL disiapkan. Kemudian pembacaan konsentrasi dengan SSA pada masing-masing larutan sebanyak 7 kali dilakukan.

\section{HASIL DAN PEMBAHASAN}

\section{Optimasi Pelarut pada Oli}

Penetapan pelarut optimal pada oli bertujuan untuk mengetahui jenis pelarut optimum yang digunakan pada penentuan logam Mangan (Mn) dalam oli lubrikan, dimana dilakukan pengukuran absorbansi pada larutan oli standar $1 \mathrm{ppm}$ menggunakan pelarut $\mathrm{n}$ heksan, MIBK dan Thinner. Penetapan pelarut optimal ini didasarkan pada jumlah absorbansi terbesar pada konsentrasi larutan yang sama.

Gambar 1 menunjukkan bahwa pada konsentrasi 1 ppm dengan perbedaan jenis pelarut menghasilkan nilai absorbansi yang berbeda yaitu, pada pelarut $n$-heksan didapatkan absorbansi 0,0101, pada pelarut MIBK didapatkan absorbansi 0,0926, dan pada pelarut Thinner didapatkan absorbansi 0,0710. Dari hasil tersebut nilai absorbansi tertinggi yang dihasilkan adalah dengan pelarut MIBK dengan nilai absorbansi 0,0926 . Hal ini yang kemudian mendasari untuk melanjutkan penelitian ini menggunakan pelarut MIBK pada tahap optimasi kinerja analitiknya.

\section{Uji Linearitas}

Linearitas diperoleh dengan memplotkan absorbansi terukur dengan konsentrasi larutan standar yang konsentrasinya dibuat meningkat menurut deret ukur (Panggabean et al., 2013). Tujuannya adalah untuk memperoleh persamaan garis linear (linearitas) yang nantinya akan digunakan untuk menentukan konsentrasi analit di dalam sampel (Harmita, 2004). Hasil pengukuran dapat dilihat pada Gambar 2.

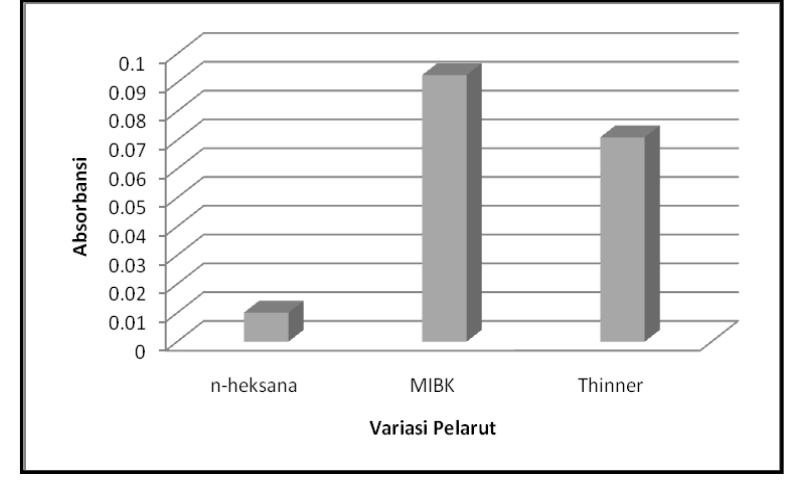

Gambar 1. Grafik Hasil Optimasi Pelarut pada Oli

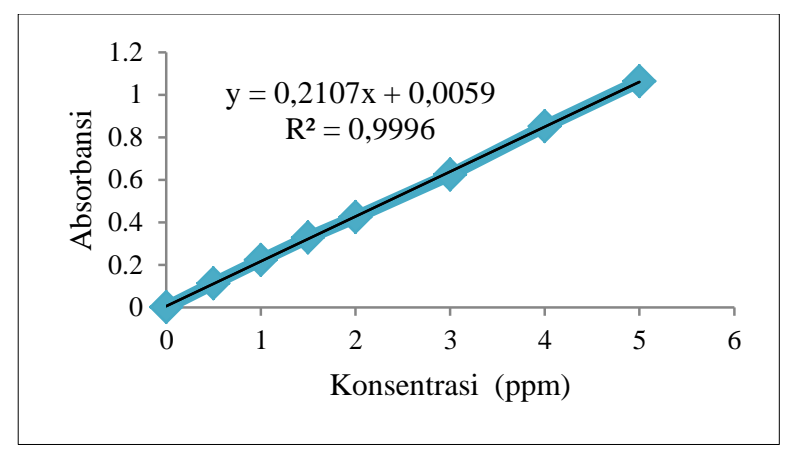

Gambar 2. Pembuatan Kurva Kalibrasi Mn dengan Metode AAS

Berdasarkan Gambar 2 persamaan garis liniear hubungan antara konsentrasi dengan absorbansi yang diperoleh adalah $\mathrm{y}=0,2107 \mathrm{x}+$ 0,0059 dengan nilai koefisien determinasi $\mathbf{R}^{2}=$ 0,9996 . Nilai $R^{2}=0,9996$ menyatakan bahwa adanya korelasi yang sangat kuat antara konsentrasi dan absorbansi. Nilai koefisien determinasi yang dapat diterima adalah apabila mendekati satu $(\approx 1)$ (Chan et al., 2004; Panggabean et al., 2014). Dalam penelitian ini hasil uji linearitas adalah $\mathrm{R}^{2} \geq 0,997$ dan sesuai syarat keberterimaan. Jadi, diketahui bahwa persamaan kurva kalibrasi telah memenuhi syarat linearitas.

\section{Uji Akurasi}

Ketepatan (akurasi) merupakan suatu besaran yang menyatakan kedekatan hasil pengukuran dengan hasil sebenarnya (standar). Akurasi dinyatakan sebagai persentase perolehan kembali (\% recovery) (Riyanto, 2014). Pada uji akurasi dilakukan dengan pengukuran sampel yang telah ditambahkan standar sebanyak $1 \mathrm{~mL}$ dengan 10 kali pembacaan sampel. Hasil pengukuran dapat dilihat pada Tabel 2. Pada parameter akurasi didapatkan nilai \% recovery 
Rona M. Napitupulu dkk. / Indo. J. Chem. Res., 2019, 6(2), 94-100

rata-rata adalah $85,62 \pm 2,09$. Menurut Riyanto (2014), suatu metode dikatakan valid apabila nilai perolehan kembali dari suatu standar berada diantara $80-110 \%$ dapat dilihat bahwa nilai yang diperoleh dapat diterima karena masih dalam interval syarat keberterimaan dimana nilai \% recovery yang diperoleh dalam rentang 82,25$88,34 \%$ yang menunjukkan nilai akurasi yang diperoleh baik.

\section{Uji Presisi}

Dalam uji presisi, parameter yang diukur adalah nilai repitibilitas dan reprodusibilitas. Nilai repitibilitas dan reprodusibilitas diperoleh dengan mengukur konsentrasi Mn yang terdapat pada sampel sebanyak 10 kali pada hari yang yang sama (hari pertama) dan juga pada hari yang berbeda (hari kedua). Hasil uji presisi ditampilkan pada Tabel 3.

Tabel 2. Hasil Uji Akurasi

\begin{tabular}{cccc}
\hline $\begin{array}{c}\text { Konsentrasi } \\
\text { Sampel (ppm) }\end{array}$ & $\begin{array}{c}\text { Konsentrasi Sampel + } \\
\text { Standar (ppm) }\end{array}$ & $\begin{array}{c}\text { Konsentrasi } \\
\text { Terukur (ppm) }\end{array}$ & \% Recovery \\
\hline 0,3724 & 1,1949 & 0,8225 & 82,25 \\
0,3710 & 1,2113 & 0,8403 & 84,03 \\
0,3697 & 1,2166 & 0,8469 & 84,69 \\
0,3713 & 1,2322 & 0,8609 & 86,09 \\
0,3700 & 1,2366 & 0,8666 & 86,66 \\
0,3717 & 1,2448 & 0,8731 & 87,31 \\
0,3697 & 1,2531 & 0,8834 & 88,34 \\
\hline Rata-rata & & $0,8562 \pm 0,0209$ & $85,62 \pm 2,09$ \\
\hline
\end{tabular}

Tabel 3. Hasil Uji Presisi

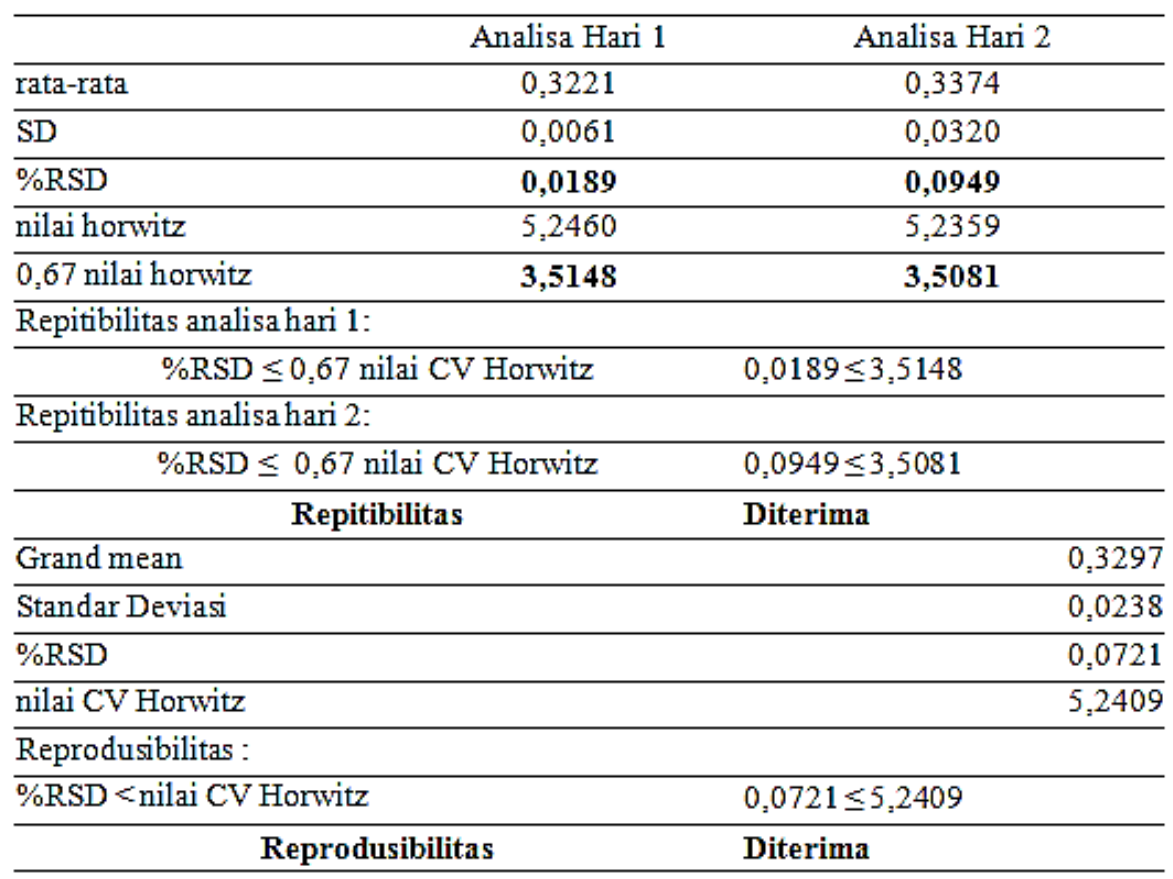


Rona M. Napitupulu dkk. / Indo. J. Chem. Res., 2019, 6(2), 94-100

Tabel 4. Hasil Uji LOD dan LOQ

\begin{tabular}{ccccc}
\hline $\mathrm{n}$ & Konsentrasi (ppm) & Absorbansi & Yi & $(\mathrm{Y}-\mathrm{Y} 1)^{2}$ \\
\hline 1 & 0 & 0,002 & 0,0078 & 0,0000003 \\
2 & 0,5 & 0,1134 & 0,113 & 0,0000003025 \\
3 & 1 & 0,2217 & 0,218 & 0,0000144400 \\
4 & 1,5 & 0,3291 & 0,323 & 0,0000378225 \\
5 & 2 & 0,4237 & 0,428 & 0,0000184900 \\
6 & 3 & 0,6239 & 0,638 & 0,0002016400 \\
7 & 4 & 0,8512 & 0,848 & 0,0000090000 \\
8 & 5 & 1,0638 & 1,058 & 0,0000302500 \\
\hline Jumlah & 17 & 3,6288 & 3,626 & 0,00031195 \\
\hline SD & 0,007 \\
\hline LOD & $\mathbf{0 , 0 9 5} \mathbf{~ p p m}$ \\
\hline LOQ & $\mathbf{0 , 3 1 7} \mathbf{~ p p m}$ \\
\hline
\end{tabular}

Tabel 5. Hasil Uji MDL

\begin{tabular}{|c|c|c|c|}
\hline $\begin{array}{l}\text { Konsentrasi } \\
\text { sampel (ppm) }\end{array}$ & $\begin{array}{c}\text { Konsentrasi } \\
\text { sampel+std (ppm) }\end{array}$ & $\begin{array}{l}\text { Konsentrasi terukur } \\
\text { (ppm) }\end{array}$ & $\%$ Recovery \\
\hline 0,2478 & 0,3018 & 0,0540 & 90,00 \\
\hline 0,2495 & 0,3067 & 0,0572 & 95,33 \\
\hline 0,2502 & 0,3119 & 0,0617 & 102,83 \\
\hline 0,2622 & 0,3233 & 0,0611 & 101,83 \\
\hline 0,2718 & 0,3326 & 0,0608 & 101,33 \\
\hline 0,2504 & 0,3119 & 0,0615 & 102,50 \\
\hline 0,261 & 0,3187 & 0,0577 & 96,17 \\
\hline Rata-rata & & 0,0591 & 98,57 \\
\hline standar deviasi ( & & 0,0029 & \\
\hline $\mathrm{MDL}=3,143 \times \mathrm{s}$ & & 0,0092 & \\
\hline CV Horwitz & & 5,6140 & \\
\hline$\% \mathrm{RSD}$ & & 0,0493 & \\
\hline \multicolumn{4}{|c|}{ Syarat Keberterimaan MDL } \\
\hline \multicolumn{2}{|c|}{ 1)MDL $\times 10>$ Spike } & $0,0920>0,06$ & Diterima \\
\hline \multicolumn{2}{|l|}{ 2) $\mathrm{MDL}<$ Spike } & $0,0092<0,06$ & Diterima \\
\hline \multicolumn{2}{|c|}{ 3) $\%$ Recovery $=80-110 \%$} & $98,57 \%$ & Diterima \\
\hline \multicolumn{2}{|l|}{ 4) $\% \mathrm{RSD} \leq 20 \%$} & $0,0493 \%<20 \%$ & Diterima \\
\hline \multicolumn{2}{|c|}{ 5)\%RSD < CV Horwitz } & $0,0493<5,6140$ & Diterima \\
\hline
\end{tabular}

Berdasarkan Tabel 3, uji repitibilitas dapat diterima karena telah memenuhi syarat yaitu pada analisa hari 1 dan analisa hari 2 nilai $\%$ RSD $\leq 0,67$ nilai $\mathrm{CV}$ horwitz. Pada uji reprodusibilitas dapat diterima karena telah memenuhi syarat yaitu \% RSD < Nilai Horwitz dimana nilai \% RSD yang dihasilkan ialah 0,0721 dan nilai Horwitz yang dihasilkan 5,2409.
Sehingga dapat disimpulkan metode ini dapat dinyatakan memiliki presisi yang baik.

\section{Uji LOD dan LOQ}

Uji Limit of Detection (LOD) dan Limit of Quantity (LOQ) dilakukan secara statistik menggunakan kurva standar Mn (mangan). Kemudian didapatkan nilai simpangan baku yang digunakan untuk penentuan nilai LOD dan LOQ. 
Hasil uji LOD dan LOQ dapat dilihat pada Tabel 4.

Berdasarkan hasil perhitungan pada Tabel 4, diperoleh nilai limit deteksi pada Mn dalam oli lubrikan menggunakan spektrofotometer serapan atom adalah 0,095 ppm dengan limit kuantisasi sebesar 0,317 ppm. Berdasarkan Kantasubrata (2012), dinyatakan bahwa limit deteksi adalah konsentrasi terendah dari analit dalam sampel yang dapat terdeteksi sedangkan limit kuantisasi atau yang biasa disebut limit pelaporan adalah konsentrasi terendah dari analit dalam sampel yang dapat ditentukan dengan tingkat akurasi dan presisi yang diterima. Semakin kecil nilai LOD/LOQ, menunjukkan detektor dan metode yang digunakan semakin teliti, karena mampu mengukur jumlah analit hinggal level trace (Panggabean et al., 2018). Maka untuk analisis Mn dalam oli lubrikan dengan AAS serapannya masih dat dibaca hingga batas konsentrasi sebesar 0,095 ppm dan pada batas kuantisasi sebesar 0,317 ppm yang merupakan konsentrasi analit terendah yang dapat terkuantisasi, jadi untuk melakukan analisa logam mangan dalam oli lubrikan menggunakan spektrofotometer serapan atom, konsentrasi yang disarankan yaitu di atas 0,317 ppm.

\section{Uji IDL (Instrument Detection Limit) dan MDL (Method Detection Limit)}

Pada uji IDL dilakukan pembacaan blanko sebanyak 10 kali sehingga didapatkan nilai standar deviasi yaitu 0,007 dengan nilai IDL yaitu $0,021 \mathrm{ppm}$. Nilai IDL ini digunakan untuk menentukan estimasi konsentrasi untuk menentukan MDL. Hasil pengukuran dapat dilihat pada Tabel 5.

Pada uji MDL (Method Detection Limit), dilakukan metode spike yang didasarkan pada nilai IDL. Nilai IDL yang diperoleh digunakan untuk menentukan estimasi nilai MDL untuk menetukan konsentrasi target pada metode spike yang akan dilakukan (Purwanto dkk., 2007). Dalam penelitian ini didapatkan hasil estimasi nilai MDL adalah $0,06 \mathrm{ppm}$. Nilai rata-rata persen perolehan kembali untuk penambahan analit pada sampel dengan nilai $1 \mathrm{ppm}$ adalah 80-110 \% (Tabel 5), selain itu semua parameter pada syarat keberterimaan MDL menghasilkan data yang diterima sesuai dengan syarat keberterimaanya. Sehingga metode ini dinyatakan memiliki nilai IDL dan MDL yang baik.

\section{KESIMPULAN}

Penentuan Mn dalam oli lubrikan dengan metode pengenceran langsung menggunakan spektrofotometer serapan atom (AAS) memiliki hasil uji yang valid, ditunjukkan dari hasil pengukuran nilai parameter-parameter pengukuran yang meliputi liniearitas, IDL (Instrument Detection Limit) dan MDL (Methode Detection Limit) akurasi, presisi, LOD (Limit of Detection) serta LOQ (Limit of Quantitation), yang secara keseluruhan dapat diterima dan dinyatakan valid.

\section{UCAPAN TERIMA KASIH}

Penulis mengucapkan terima kasih kepada Pimpinan dan Staf PT. Badak NGL Bontang, Kalimantan Timur untuk fasilitas laboratorium dan sampel yang disediakan dalam pelaksanaan penelitian ini.

\section{DAFTAR PUSTAKA}

Anonim,1996, Analytical Methods for Atomic Absorption Spectroscopy, Perkin-Elmer Corporation, USA.

Adha, L.S., Panggabean, A.S. Kartika, R, 2017, Optimasi Kinerja Analitik Terhadap Penentuan Kadar Fluorin Pada Batubara Dengan Metode Spektrofotometer Visible, Jurnal Atomik, 2(1), 143-145.

Binudi, R, 2014, Pengaruh Unsur $\mathrm{Ni}, \mathrm{Cr}$ dan Mn terhadap Sifat Mekanik Baja Kekuatan Tinggi Berbasis Laterit, Pusat Penelitian Metalurgi LIPI Tangerang Selatan.

Chan, C.C, H.L.Y. C. LEE, X. Zhang, 2004, Analytical Method Validation and Instrumental Performent Verification, Willey Intercine A. John Willy and Sons. Inc. Publication.

Destiana, L.V., Panggabean, A.S., Kartika, R, 2017, Pengembangan Metode Rapid Test Preparation Dalam Penentuan Kadar Inherent Moisture Dan Total Sulfur Dengan Metode Yang Dipergunakan Oleh Iso (International Organization For Standardization, Jurnal Atomik, 2(1), 175182. 
Harmita, 2004. Petunjuk Pelaksanaan Validasi Metode dan Cara Perhitungannya, Majalah Ilmu Kefarmasian, 1(3), 117-135.

Kantasubrata, J, 2012, Validasi Metode. Pelatihan Pemahaman dan Penerapan SNI ISO/IEC 17025:2008 Pada Pengelolaan Laboratorium, RC Chem Learning Centre. Bandung.

Panggabean, A.S., Pasaribu, S.P., Amran, M.B., Buchari, 2013, Gas-liquid Separator Integrated to HG-QFAAS Method for Determination of Tin at Trace Levels in The Water Samples, Indones. J. Chem. Sci., 8(1), 17-27.

Panggabean, A. S., Pasaribu, S., Bohari, Nurhasanah, 2014, Preconcentration of Chromium (VI) at Trace Levels Using Acid Alumina Resin With Column Method, Indones. J. Chem., 14(1), 51-56.

Panggabean, A. S, Pasaribu, S. P., Kristiana, F., 2018, The Utilization of Nitrogen Gas a Carrier Gas in Determination of $\mathrm{Hg}$ Ions Using Cold Vapor-Atomic Absorption Spectrophotometer (CV-AAS), Indones. J. Chem., 18 (2), 279-285.
Purwanto A, Supriyanto C dan Samin P, 2007, Validasi Pengujian $\mathrm{Cr}, \mathrm{Cu}$ Dan $\mathrm{Pb}$ Dengan Metode Spektrometri Serapan Atom, Pustek Akselerator, 6(1), 121-125.

Riyanto, 2014, Validasi \& Verifikasi Metode Uji sesuai dengan ISO/IEC 17025 Laboratorium pengujian dan Kalibrasi, Deepublish, Yogyakarta.

Supriyanto, A. Alimuddin, Bohari, Y., 2016, Analisis Logam $\mathrm{Fe}, \mathrm{Cu}, \mathrm{Pb}$ dan $\mathrm{Zn}$ dalam Minyak Pelumas Baru dan Bekas Menggunakan X-Ray Fluorescence, Jurnal Atomik, 3(1), 13-17.

Taufiq, M., Sabarudin. A., Mulyasuryani, A., 2016, Pengembangan dan Validasi Metode Destruksi Gelombang Mikro untuk Penentuan Logam Berat Kadmium dan Timbal dalam Cokelat dengan Spektoskopi Serapan Atom (SSA), Alchemy Jurnal Penelitian Kimia, 5(2), 31-37. 